\title{
Algorithm for the referral of patients with inflammatory back pain from primary care in Malaysia
}

\author{
Ing Soo Lau, Suk Chyn Gun, Swan Sim Yeap, Mollyza Mohd Zain, Habibah Mohd Yusoof, \\ Sargunan Sockalingam, Fariz Bin Yahya
}

Lau IS, Gun SC, Yeap SS, et al. Algorithm for the referral of patients with inflammatory back pain from primary care in Malaysia. Malays Fam

Physician. 2021;16(2);2-6. https://doi.org/10.51866/rv1206

Keywords:

Inflammatory back pain,

3R algorithm, primary

care, referral, axial

spondyloarthritis

\section{Authors:}

\section{Lau Ing Soo}

(Corresponding author)

Hospital Selayang, Selangor

Malaysia

Email: benjhn@hotmail.com; lavis@gmail.com

\section{Gun Suk Chyn}

Hospital Tuanku Ja'afar, Seremban

Malaysia

\section{Yeap Swan Sim \\ Subang Jaya Medical Centre \\ Selangor, Malaysia}

Mollyza Mohd Zain

Hospital Selayang, Selangor

Malaysia

Habibah Mohd Yusoof

Hospital Selayang, Selangor

Malaysia

\section{Sargunan Sockalingam}

University Malaya Medical Centre

Kuala Lumpur, Malaysia

Fariz Bin Yahya

University Malaya Medical Centre

Kuala Lumpur, Malaysia

\begin{abstract}
Chronic low back pain, defined as back pain lasting for more than three months, can be divided into mechanical or inflammatory back pain (IBP). IBP typically starts in patients below the age of 40 , is improved with activity and worsens with rest. IBP is strongly associated with axial spondyloarthritis. Early recognition of IBP among primary care physicians is essential for timely diagnosis and intervention to ensure the best outcomes for patients with axial spondyloarthritis. This paper describes the Malaysian Society of Rheumatology's recently developed Inflammatory Back Pain Referral Algorithm for primary care physicians, which aims to facilitate the early identification and referral of IBP patients to rheumatologists.
\end{abstract}

\section{Introduction}

Back pain is common worldwide. The prevalence of low back pain in developed countries has been estimated to range from 10 to $30 \% .{ }^{1}$ In Malaysia, the prevalence of back pain was found to be $12 \%$, and it was the fifth and ninth most common complaint in the private and public primary healthcare settings, respectively. ${ }^{2}$ The challenge in managing back pain is to differentiate between those with serious underlying pathology and those without. The Malaysian low back pain management guideline was first published in 2010 by the Malaysian Association for the Study of Pain in collaboration with the Spine Society of Malaysia. ${ }^{3}$ These guidelines covered the management of low back pain in general, however, with no focus on chronic inflammatory back pain.

Chronic low back pain (CLBP) is defined as back pain persisting for more than three months. In comparison to acute back pain, the management of CLBP may last years. CLBP is associated with significant morbidity, as it may lead to diminished mobility and work absenteeism, in addition to increasing healthcare utilisation. ${ }^{4}$ To reduce the adverse sequelae of CLBP, early diagnosis and treatment are essential.

Many patients with CLBP will present to primary care physicians (PCPs) as a first line. The purpose of the initial assessment by PCPs is to triage patients into those with specific pathology (up to 10\%) and those with non-specific LBP (approximately 90\%), after exclusion of possible pathology. ${ }^{5}$ A subset of patients with CLBP have features suggestive of inflammatory back pain (IBP), so it is important to recognise that IBP usually presents with CLBP. ${ }^{6,7}$

Inflammatory back pain is the key clinical symptom for axial spondyloarthritis (axSpA), which includes ankylosing spondylitis and nonradiographic spondyloarthritis. ${ }^{6}$ Symptoms of IBP are usually localised to the axial spine and sacroiliac joints and are differentiated from mechanical back pain. Symptoms of IBP include insidious onset of back pain, morning stiffness in the lower back for more than 30 minutes, improvement of back pain with exercise, no improvement with rest, awakening at night or in the early morning because of back pain and alternating buttock pain. ${ }^{8}$ In primary care, it is estimated that $5 \%$ of patients with CLBP have axSpA. The presence of IBP symptoms increases the likelihood of axSpA by $9-11 \% .^{7}$ Interestingly, it has been found that $36 \%$ of Asian populations with IBP also meet the criteria for spondyloarthropathy. ${ }^{8}$

This has led to the proposed development of a 
referral tool with the aim to facilitate the early identification and referral of IBP patients to rheumatologists for further detailed assessment, ensuring that patients diagnosed with axSpA receive appropriate treatment early.

\section{Methods}

A steering committee meeting consisting of seven leading Malaysian experts in rheumatology (LIS, GSC, YSS, MMZ, HMY, SS and FY) and three independent scientific assistants (LSL, CBJ and SM) was convened in October 2019 in Kuala Lumpur, Malaysia. Each of the seven experts had over 10 years of experience treating patients with IBP and patients with axSpA. The experts aimed to develop a feasible referral tool to facilitate the referral of IBP patients based on evidence from the literature, along with their expert clinical opinions.

The panel of seven rheumatologists subsequently participated in further rounds of discussion via email, along with evaluation of all literature concerning IBP published up to and including October 2019. The steering committee discussed the results thoroughly, taking into account the feasibility of local clinical practice, until a consensus was achieved. This led to the formulation of the Inflammatory Back Pain Recognise - Review - Refer (IBP 3R) referral algorithm.

The algorithm was subsequently validated with input from a group of primary care physicians before being formalised. The referral tool focused on (1) adapting the most appropriate criteria for IBP use in the Malaysian setting, (2) using available resources and appropriate investigations to help with the referral process and (3) choosing the appropriate specialist when referring patients presenting with IBP.

\section{Results}

\section{Consensus findings}

Several main considerations were specified in the process of developing the referral algorithm. These were discussed in the three different key steps of the algorithm: (1) Recognise, (2) Review and (3) Refer (Figure 1).

\section{Recognise}

There have been several criteria developed previously to measure and assess IBP to identify patients that may require a more detailed assessment of axSpA. These include the criteria developed by Calin in $1977,{ }^{9}$ the
Amor criteria in $1990,{ }^{10}$ the Berlin criteria in $2006^{11}$ and the most recent ASAS criteria for IBP in 2009. ${ }^{12}$ The expert group agreed that the use of the ASAS IBP criteria in assessing IBP in Malaysia was most appropriate, as it has been found to be robust and easy to apply, with good specificity and sensitivity. ${ }^{6,12,13}$ The five ASAS criteria for IBP are (1) onset of pain at age $<40$ years, (2) gradual onset, (3) improvement of pain with exercise, (4) no improvement with rest and (5) pain at night. If at least four out of these five parameters are fulfilled, a sensitivity of $77.0 \%$ and a specificity of $91.7 \%$ are implied for the presence of IBP, but not for the diagnosis of axSpA. ${ }^{12,14}$ Patients who fulfil these criteria should then be evaluated further, as stipulated in the 'Review' step.

\section{Review}

This step takes into account feasibility within local practice. The expert group agreed that additional information including further clinical history, further basic blood and/or radiographic investigations, and any significant associated features of spondyloarthritis present should be obtained. Information regarding clinical history and symptoms include the location, nature and duration of pain, any family history of rheumatological disorders and treatment used for IBP.

The steering committee also agreed that key investigations that should be considered include inflammatory markers such as erythrocyte sedimentation rate (ESR) or C-reactive protein (CRP). Although CRP may not be readily available in certain healthcare facilities in Malaysia, the use of ESR as an alternative was considered acceptable by the expert group. This takes into consideration that an objective measure of inflammation is indicative of active inflammation that could be due to axSpA. ${ }^{15}$ This is also useful because ESR and/or CRP are components used to assess disease activity scores in axSpA. ${ }^{16,17,18}$

Radiographic assessments have been used in the modified New York Criteria for the diagnosis of ankylosing spondylitis. ${ }^{19}$ In contrast, the availability of MRI for assessment of inflammation has been adapted into the ASAS 2009 classification criteria. $^{20}$ Taking into consideration the limited access to MRI in certain regions of Malaysia, the steering committee agreed that an x-ray of the sacroiliac (SI) joints is an acceptable assessment that can be requested by the referring physician. ${ }^{21}$ 
It is important to note, however, that a normal X-ray of the SI joints does not rule out the possibility of a diagnosis of axSpA. ${ }^{22}$ Further detailed assessments by MRI may be requested by the rheumatologists as part of their detailed assessment. In addition, patients with 'red flag' symptoms (including acute onset pain, fever, unexplained weight loss, incontinence, history of malignancy, unilateral SI joint pain likely consistent with infection) should be referred urgently to the respective secondary care specialists for further assessment. ${ }^{23}$

\section{Refer}

In the final step of the algorithm, patients with suspected inflammatory back pain should be referred to a rheumatologist for further investigation and management.
A comprehensive list of hospitals with rheumatology services across Malaysia can be obtained from the Malaysian Society of Rheumatology website (https://msr.my/ rheumatology-services/list-of-hospitals/). A link for this has been embedded in the referral IBP $3 R$ algorithm in the form of a $Q R$ code (Figure 1). The steering committee agreed, however, that patients who are to be referred may receive non-steroidal anti-inflammatory (NSAIDs) treatment and physiotherapy prior to attending a rheumatology specialist clinic.

The application of the proposed referral algorithm is believed to be easily administered by primary care physicians, orthopaedic surgeons and even other specialties to determine whether a patient's IBP is indicative of axSpA.

\section{Inflammatory Back Pain 3R Algorithm}
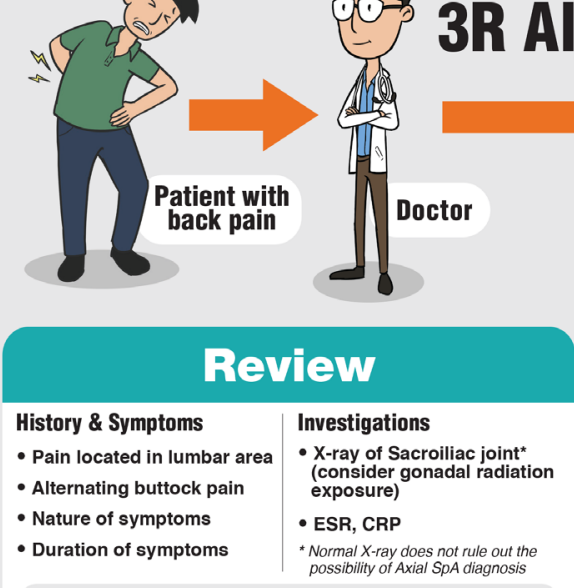

Other information

- Family history of rheumatological disorder, psoriasis or other autoimmune condition

- Associated symptoms eg. Uveitis, psoriasis, peripheral

joint inflammation, features of inflammatory bowel disease

- Treatments used thus far

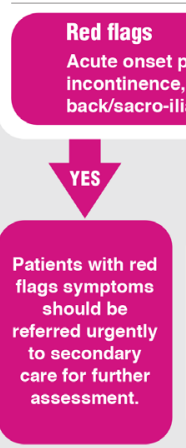

Red flags

Acte onset pain, fever, unexplained weight loss, back/sacro-iliac joint pain. atients with red

should be

to secred urgentiy
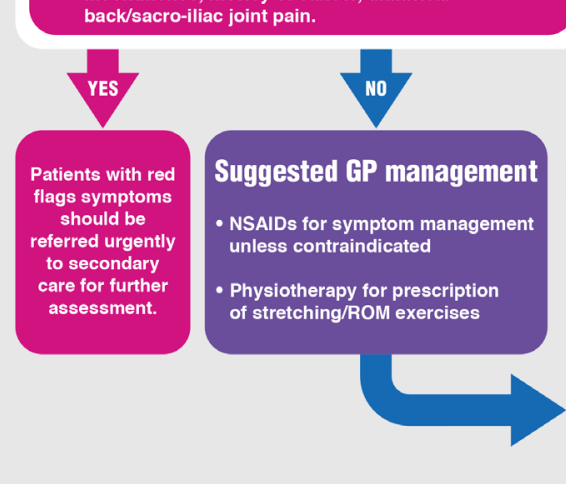

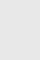

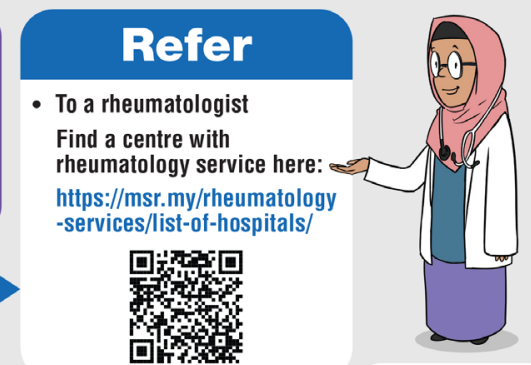

Rheumatologist

Figure 1: Inflammatory Back Pain 3R (Recognise-Review-Refer) algorithm 


\section{Discussion}

Patients with IBP usually present in their mid$20 s^{24}$, thus affecting individuals at the prime of their lives. A delayed diagnosis may also potentially lead to unfavourable socioeconomic consequences. Patients will suffer pain, stiffness, fatigue, and a loss of spinal function and mobility, leading to a reduction in quality of life $e^{25}$, work productivity ${ }^{26}$, and an increase in direct and indirect medical costs. ${ }^{27}$ Studies have shown that there is an unacceptably long delay, averaging eight to 11 years $^{6}$, between the onset of symptoms and the time to diagnosis of axSpA. Such a long delay in diagnosis will lead to poor functional outcomes among patients. Early diagnosis of axSpA is therefore crucial to ensure timely treatment, which is associated with improved outcomes.

The steering committee sought to leverage the knowledge and clinical experience of local experts who treat patients with IBP as part of their daily clinical practice in the development of a referral tool that is both feasible and easy to use. In the past few years, the use of new treatments such as biologics can effectively control signs and symptoms of arthritis whilst delaying disease progression. ${ }^{28,29}$ This has led to significantly improved treatment outcomes of axSpA. In view of the importance of early treatment, the IBP 3R Algorithm is introduced with the aim of facilitating primary care physicians and other specialties in the early identification and referral of IBP patients to rheumatologists for further investigation and management.

Axial spondyloarthritis has been well established to be associated with the presence of the genetic marker HLA-B27. ${ }^{30}$ A positive HLA-B27 test with no clinical features does not, however, indicate the diagnosis of axSpA. HLA-B27 genetic testing is thought to be of relevance if patients develop IBP symptoms; however, the relatively high cost and limited availability of HLA-B27 testing in certain regions of Malaysia are seen as challenges to incorporating the HLA-B27 parameter into the IBP 3R algorithm. For now, it may be more practical for HLA-B27 testing to be requested by the rheumatology specialist, although other specialists or primary care physicians may request it if they have the available resources to do so.

\section{Conclusion}

In view of the importance of early treatment of axSpA in achieving better outcomes, efforts to reduce the delay in disease diagnosis are imperative. One such way is to encourage early referral to rheumatology specialist clinics via the use of a feasible tool such as the IBP $3 R$ algorithm to facilitate early IBP identification among patients with back pain. This ensures timely assessment and proper disease intervention, which can significantly improve overall prognosis.

\section{Conflicts of Interest}

The authors declare no conflicts of interest.

\section{Authors' Contributions}

All the authors have contributed to and approved the content of the paper.

\section{Acknowledgments}

The expert panel discussion and the preparation of this manuscript were funded by Novartis (Malaysia). The authors acknowledge manuscript writing assistance from Siew $\mathrm{Li}$ Lai, Bao Jing Chen and Suryaprakash Mishra.

\section{References}

1. Walker BF. The prevalence of low back pain: A systematic review of the literature from 1966 to 1998. Clin Spine Surg. 2000; 13(3): 205-217.

2. Sivasampu S, Yvonne L, Norazida AR, et al. National Medical Care Statistics (NMCS), Kuala Lumpur: National Clinical Research Centre; 2014.

3. The Malaysian Low Back Pain Management Guidelines (First edition). 2010. Available at https://www.masp.org.my/index. cfm? menuid $=23$.
4. Walker BF, Muller R, Grant WD. Low back pain in Australian adults: Prevalence and associated disability. J Manipulative Physiol Ther. 2004; 27(4): 238-44.

5. Bardin LD, King P, Maher CG. Diagnostic triage for low back pain: A practical approach for primary care. Med J Aust 2017; 206(6): 268273 .
6. Poddubnyy D, Callhoff J, Spiller I, et al. Diagnostic accuracy of inflammatory back pain for axial spondyloarthritis in rheumatological care. RMD Open. 2018; 4: e000825. doi:10.1136/ rmdopen-2018-000825

7. J Sieper, M Rudwaleit. Early referral recommendations for ankylosing in primary care. Ann Rheum Dis. 2005; 64: 659-663. doi: 10.1136/ard.2004.028753 
8. Lassiter W, Allam AE. Inflammatory back pain. Treasure Island: Statpearls Publishing; 2019.

9. Calin A, Porta J, Fries JF, et al. Clinical history as a screening test for ankylosing spondylitis. Jama. 1977; 237(24): 2613-2614.

10. Amor B, Dougados M, Mijiyawa M. Criteria of the classification of spondylarthropathies. Revue du rhumatisme et des maladies osteoarticulaires. 1990; 57(2): 85-89.

11. Rudwaleit M, Metter A, Listing J, et al. Inflammatory back pain in ankylosing spondylitis: A reassessment of the clinical history for application as classification and diagnostic criteria. Arthritis Rheum. 2006; 54(2): 569-578.

12. Sieper J, van der Heijde D, Landewé R, et al. New criteria for inflammatory back pain in patients with chronic back pain: A real patient exercise by experts from the Assessment of SpondyloArthritis international Society (ASAS). Ann Rheum Dis. 2009; 68: 784-788

13. Feldtkeller E, Khan MA, van der Heijde D, et al. Age at disease onset and diagnosis delay in HLA-B27 negative vs. positive patients with ankylosing spondylitis. Rheumatol Int. 2003; 23: 61-66. DOI 10.1007/s00296-002-0237-4

14. Poddubnyy D. Classification vs diagnostic criteria: The challenge of diagnosing axial spondyloarthritis. Rheumatology. 2020; 59(Supplement_4): iv6-17.

15. Biomarkers Definitions Working Group. Biomarkers and surrogate endpoints: Preferred definitions and conceptual framework. Clin Pharmacol Ther. 2001; 69: 89-95.
16. Brown MA, Li Z, Lê Cao KA. Biomarker development for axial spondyloarthritis. Nat Rev Rheumatol. 2020; 16(8): 448-63.

17. Lukas C, Landewé R, Sieper J, et al. Development of an ASAS-endorsed disease activity score (ASDAS) in patients with ankylosing spondylitis. Ann Rheum Dis. 2009; 68(1): 18-24.

18. van der Heijde D, Lie E, Kvien TK, et al ASDAS, a highly discriminatory ASASendorsed disease activity score in patients with ankylosing spondylitis. Ann Rheum Dis. 2009; 68(12): 1811-1818.

19. Linden SV, Valkenburg HA, Cats A. Evaluation of diagnostic criteria for ankylosing spondylitis. Arth \& Rheum. 1984; 27(4): 361-8.

20. Rudwaleit M, Jurik AG, Hermann KA, et al. Defining active sacroiliitis on magnetic resonance imaging (MRI) for classification of axial spondyloarthritis: A consensual approach by the ASAS/OMERACT MRI group. Ann Rheum Dis. 2009; 68(10): 1520-7.

21. Rudwaleit M, van der Heijde D, Khan MA, et al. How to diagnose axial spondyloarthritis early. Ann Rheum Dis. 2004; 63: 535-543. doi: 10.1136/ard.2003.011247

22. Protopopov M, Poddubnyy D. Radiographic progression in non-radiographic axial spondyloarthritis. Expert Rev Clin Immunol. 2018; 14(6): 525-533. DOI:10.1080/174466 6X.2018.1477591

23. The Outpatient GP Referral Guidelines Rheumatology for Chronic Back Pain. Available at https://www.sahealth.sa.gov.au/
24. Sieper J, Rudwaleit M. Early referral recommendations for ankylosing spondylitis (including pre-radiographic and radiographic forms) in primary care. Ann Rheum Dis. 2005; 64: 659-63. doi:10.1136/ard.2004.028753

25. Kotsis K, Voulgari PV, Drosos AA, et al. Health-related quality of life in patients with ankylosing spondylitis: A comprehensive review. Expert Rev Pharmacoecon Outcomes Res. 2014; 14(6): 857-72.

26. Martindale J, Shukla R, Goodacre J. The impact of ankylosing spondylitis/axial spondyloarthritis on work productivity. Best Pract Res Clin Rheumatol. 2015; 29: 512-23.

27. Walsh JA, Song X, Kim G, et al. Healthcare utilization and direct costs in patients with ankylosing spondylitis using a large US administrative claims database. Rheumatol Ther. 2018; 5(2): 463-474.

28. Sepriano A, Regel A, van der Heijde D, et al. Efficacy and safety of biological and targetedsynthetic DMARDs: A systematic literature review informing the 2016 update of the ASAS/ EULAR recommendations for the management of axial spondyloarthritis. RMD Open. 2017; 3(1).

29. Baraliakos X, Gensler LS, D’Angelo S, et al. Biologic therapy and spinal radiographic progression in patients with axial spondyloarthritis: A structured literature review. Ther Ad Musculoskelet Dis. 2020; 12: 1759720X20906040.

30. Brown MA. Genetics of ankylosing spondylitis. Curr Opin Rheumatol. 2010; 22(2): 126-32. 